ABORDAGEM CONTEXTUALIZADA DO TEMA AGROTÓXICOS: UMA PROPOSTA PARA O ENSINO DE QUIIMICA

\title{
CONTEXTUALIZED APPROACH OF PESTICIDES SUBJECT: A PROPOSAL FOR TEACHING CHEMISTRY
}

\author{
MEDEIROS, Maraína Souza'; GOULART, Simone Machado²*; SANTOS, João Paulo Victorino² \\ ${ }^{1}$ Universidade Federal de Uberlândia, Mestranda em Qualidade Ambiental, Avenida Amazonas, S/N, Câmpus \\ Umuarama, CEP: 38.400-902, Uberlândia - MG, Brasil
}

(fone: +55 343225 - 8444)

${ }^{2}$ Instituto Federal de Goiás - Câmpus Itumbiara, Professor(a) efetivo(a) do curso de Licenciatura em Química, Avenida Furnas, $n^{\circ} 55$, Village Imperial, CEP: 75.524-010, Itumbiara - GO, Brasil

(fone: +55 642103 - 5600)

\author{
* Autor correspondente \\ e-mail: simone.goulart@ifg.edu.br
}

Received 29 January 2016; received in revised form 28 March 2016; accepted 23 June 2016

\begin{abstract}
RESUMO
Os agrotóxicos são substâncias químicas que tem por finalidade o controle de pragas na agricultura, pecuária e para fins domissanitários. A utilização da temática como eixo norteador para se trabalhar conceitos químicos é de grande interesse na área de Ensino de Química, principalmente quando aplicada nas disciplinas de Química Ambiental, Analítica e Orgânica, visto que uma das maiores preocupações na Ciência Química é o modo como os educadores contextualizam suas disciplinas específicas com seus discentes. Nesse sentido, o trabalho objetivou investigar o tema "agrotóxicos" na literatura, bem como por meio de entrevistas com docentes da área da Química e contextualizá-lo em três áreas específicas: Ambiental, Analítica e Orgânica. Adicionalmente, foi produzido um caderno didático a partir dessas contextualizações. O tema ainda é pouco explorado em sala de aula pelos professores, entretanto esse trabalho trouxe um novo olhar ao tema e destacou sua importância regional e, principalmente, seu grande potencial para contextualização nas diversas áreas da Química. Os dados obtidos contribuíram para a construção do caderno didático, inclusive, no que diz respeito às sugestões de atividades pelos docentes. Assim sendo, o material didático produzido torna-se um mecanismo relevante para agregar conhecimentos quanto aos agrotóxicos no contexto da educação em Química.
\end{abstract}

Palavras-chave: Pesticidas; Química; Contextualização.

\begin{abstract}
Pesticides are chemicals that aim to control pests in agriculture, livestock and household cleaning purposes. The use of the theme as a guideline for working chemical concepts is of great interest in the field of Chemistry Teaching, especially when applied in the area of Environmental Chemistry, Analytical Chemistry and Organic Chemistry, as a major concern in Chemical Science is the way how educators contextualize their specific subjects with their students. After conducting interviews with six chemistry teachers who teach in Chemistry Course, the theme "pesticides" was contextualized in the specific disciplines of the Course, using data supplied by teachers and by gathering information in scientific articles and books. By this all, an educational copybook was produced.
\end{abstract}

Keywords: Pesticides; Chemistry; Contextualization. 


\section{INTRODUÇÃO}

Conforme pesquisas apontadas por Chassot (2004), buscar alternativas para melhor difusão da Ciência Química e da sua importância social no mundo atual é de responsabilidade dos educadores dessa área. Além disso, é preciso não somente destacar o papel dos educadores na divulgação dos benefícios dessa Ciência para sociedade, mas também e, principalmente, analisar criticamente as interferências da Química que, por vezes, são muito nocivas para o meio ambiente. Professores enfrentam muitos desafios ao ter que aprender a ensinar a Ciência de uma forma eficaz, envolvendo o aluno, para alcançar uma aprendizagem produtiva (Schwarz, 2009).

Os agrotóxicos são substâncias químicas que tem por finalidade o controle de pragas (animais, vegetais, bactérias ou fungos) e doenças que as plantas podem vir a adquirir. Além disso, são substâncias que representam riscos potenciais à saúde pública (WHO, 1990). Essas substâncias também são conhecidas como defensivos agrícolas, pesticidas, praguicidas, remédio de planta e veneno. A sua aplicabilidade, em termos de larga escala, é verificada tanto na agricultura quanto nas pastagens para pecuária, além de florestas nativas e plantadas, ambientes hídricos, urbanos e industriais (Peres et al., 2003). O termo agrotóxicos, portanto, inclui uma diversidade de compostos tais como inseticida, fungicida, herbicida, moluscida, nematicida e outros, dependendo da sua finalidade de uso (Aktar et al., 2009).

A utilização de temas contextualizadores para se ensinar conteúdos de Química é uma das melhores maneiras encontradas pelos docentes para chamar a atenção dos discentes, como meio de incitar o interesse pelo conteúdo proposto em sala de aula. Dentre os diversos temas contextualizadores, destacam-se os agrotóxicos. Além de ser um eixo temático social que motiva os alunos, o tema também é rico conceitualmente, o que permite ao professor desenvolver com seus alunos conteúdos químicos, biológicos, ambientais e entre outros. Essa abordagem permite aos alunos compreender a importância dos agrotóxicos na agricultura e em outros setores, além de conscientizá-los sobre o manuseio correto dessas substâncias. Como consequência, a proposta de contextualização favorece o desenvolvimento intelectual por despertar o espírito crítico do aluno para que possa intervir em diversas situações cotidianas (Cavalcanti et al., 2010).

Trabalhos relacionados ao tema agrotóxicos apontam para objetivos como conscientizar os alunos sobre as implicações do uso dos mesmos e a sua relação com conceitos químicos, principalmente para aqueles estudantes que vivenciam a agricultura local, no manuseio desses produtos, proporcionando, assim, uma aproximação do conhecimento químico com a realidade que os cercam (Braibante e Zappe, 2012).

Nesse sentido, 0 trabalho de pesquisa teve como objetivo investigar o tema de forma a promover a contextualização em três áreas específicas da Química: Química Ambiental, Analítica e Orgânica. Os dados da investigação referem-se, principalmente, às pesquisas que relacionam os agrotóxicos com o ensino de Química; informações governamentais sobre o uso de agrotóxicos no Brasil e em Goiás; principais cultivos do Estado e; conteúdos químicos que podem ser trabalhados a partir do tema. Grande parte dos dados obtidos foram alcançados mediante entrevista semi-estruturada com docentes que trabalham nas áreas citadas.

A realização da pesquisa se justificou por sua relevância científica na contextualização do tema com as disciplinas da Química, já que o aperfeiçoamento desse tipo de conhecimento pôde agregar grande valor ao corpo de investigações nas áreas específicas da Química. Além do mais, a pesquisa apresentou grande caráter social, uma vez que os resultados obtidos poderão ser disponibilizados e reproduzidos por docentes e discentes a fim de subsidiar o trabalho do educador em sala de aula, tornando o ensino contextualizado e interdisciplinar, principalmente no estado de Goiás onde os agrotóxicos são muito utilizados, indo de encontro à realidade dos docentes e discentes.

\section{Ensino de Química e a necessidade de uma abordagem contextualizada}

O Ensino de Ciências não pode ser encarado como um modo de preparar os alunos para um mundo que é estático e fixo, mas sim de 
prepará-los para lidar com as mudanças e desafios em suas vidas (Shamsudin et al., 2013).

É comum professores trabalharem conceitos químicos de forma abstrata e tradicionalista fazendo com que os alunos se distanciem cada vez mais pelo interesse em estudar a Química. Nessa perspectiva, Carraro (1997) diz que o ensino dessa forma não se torna atrativo para o aluno e nem ao menos produtivo de tal forma que possa melhorar a vivência no meio em que o mesmo está inserido. Ademais, deixa de contribuir para a formação do indivíduo como membro atuante de uma sociedade. Por isso, Al-Sabbagh (2009) enfatiza que a aprendizagem do aluno tem que ser baseada na investigação, de forma a desenvolver a curiosidade e envolvimento dos mesmos.

Por tradição, a maioria das metodologias educativas na Química se pautam em perspectivas de ensino nas quais os conhecimentos são trabalhados de forma fragmentada, o que desfavorece a inter-relação entre esses conhecimentos. Além do mais, essa incapacidade de articulação entre os conteúdos gera uma padronização curricular dos mesmos, pois é imperceptível a valorização da relação destes conteúdos com questões tecnológicas, sociais e ambientais (Marques e Silva, 2013).

Nesse sentido, Chassot (2003) diz que entender a Ciência contribui para controlar e prever as transformações que ocorrem na natureza. Dessa forma, dedicar-se à educação ambiental, como muitos trabalhos desenvolvidos nessa área, têm-se mostrado bastante significativo no que diz respeito à busca por resoluções acerca das transformações decorrentes de situações cotidianas. A exemplo disso, Preusch (2009) revela que a realização de viagens de campo, como atividade educativa diferenciada, estende a aprendizagem dos alunos e aumenta o interesse dos mesmos pela ciência, bem como de cuidar do meio ambiente. Ademais, faz com que os alunos criem conexões com o mundo real e também os expõem a diferentes possibilidades de carreira na ciência.

Assim, o Ensino de Química tem que decorrer tanto por aspectos da interdisciplinaridade como também por aspectos da contextualização. Essa abordagem conceitual, segundo Carraro (1997, p. 15) facilita as relações vividas pelos educandos, pois "a aprendizagem acontece de maneira participativa e integrada à vida, proporcionando ao aluno, um estudo da Química mais agradável".

Como estratégia de facilitar o ensino de Química em sala de aula, Udo (2011) propôs em simular a Ciência através de pacotes de software com alunos do secundário na Nigéria. Dois grupos de alunos foram analisados: o primeiro recebeu uma aula através do simulador e o outro uma aula tradicionalista (exposição oral tradicional). $O$ autor observou um efeito facilitador no desempenho dos alunos quanto à aprendizagem de conceitos de Química no primeiro grupo, independentemente do gênero dos alunos. Além disso, o envolvimento dos mesmos na aula foi bem mais evidente do que na aula tradicionalista.

\section{Química Ambiental, Analítica e Orgânica: uma proposta para o ensino de agrotóxicos}

A Química Ambiental é responsável por estudar fenômenos químicos e bioquímicos que acontecem na natureza, sejam eles naturais ou causados pela ação do homem e que podem comprometer não somente a saúde do ser humano, como também de todo planeta (Baird e Cann, 2011). A Química Analítica segundo Higson (2009), em contrapartida, estuda aspectos qualitativos (análises e estudos da composição de amostras) e quantitativos (quantificação de um determinado elemento em uma amostra - gravimetria). Já a Química Orgânica é responsável por estudar substâncias compostas por carbono que são comumente conhecidas como compostos orgânicos (Solomons e Fryhle, 2012). Tendo em vista essas definições, o uso do tema agrotóxicos aplicado às três áreas viabiliza uma investigação rica em conceitos químicos como também promove a aproximação da vivência do investigador com a Química.

A temática citada tem sido muito investigada pelas universidades em geral, uma vez que existe uma grande preocupação pelos pesquisadores em elaborar trabalhos que auxiliem o professor no tratamento da Química em todos os níveis de educação. A abordagem interdisciplinar de conteúdos da área torna-se relevante a partir do momento que se leva em consideração a inter-relação de tais conteúdos com os do cotidiano, inclusive, quando se explora conceitos de Química mediante uma 
temática social como os agrotóxicos. São possíveis de serem explorados conceitos de Química, tais como: átomos, moléculas e substâncias e suas relações com os princípios ativos dos agrotóxicos; funções orgânicas e agrotóxicos; análise de agrotóxicos em solo, água, alimentos e fluidos biológicos; historicidade desses agroquímicos e a valorização da educação ambiental no controle de acidentes com trabalhadores rurais e na preservação dos recursos naturais (Braibante e Zappe, 2012). Nessa perspectiva, é possível verificar que a utilização do tema como eixo norteador no tratamento de conceitos científicos no Ensino de Química favorece uma atuação mais estimulante dos alunos e, além disso, promove o objetivo da interdisciplinaridade de conteúdos.

\section{A importância dos agrotóxicos na sociedade}

Com o crescimento contínuo da população mundial e, principalmente, devido ao aumento da demanda por alimentos, tem favorecido o desenvolvimento de sistemas agrícolas cada vez mais sofisticados e eficientes. Nesse sentido, o uso de agrotóxicos como alternativa para o controle de pragas durante o cultivo e após a colheita tornou-se uma ferramenta essencial tanto para garantir o crescimento da produção agrícola quanto para aumentar a qualidade da mesma (Chiaradia, 2009). Nos Estados Unidos, por exemplo, boa parte das culturas de alimentos comercializadas utiliza algum tipo de agrotóxico, com exceção das fazendas de cultivo de produtos orgânicos, as quais utilizam pesticidas naturais (Baird e Cann, 2011). No entanto, para garantir máximos benefícios pelo uso de agrotóxicos, em um mínimo custo ambiental e econômico, é necessário que sejam manuseados por pessoas devidamente treinadas e equipadas, se possível em estreita ligação com tecnologias complementares (Cooper e Dobson, 2007).

Apesar de os agrotóxicos serem extremamente importantes para o aumento da produtividade e na eliminação de organismos vivos que atrapalham o crescimento dos cultivos, há vários problemas associados à sua aplicação, tais como: a contaminação do ambiente pelo descarte inadequado dessas substâncias em recursos hídricos e/ou solos; efeitos adversos à saúde dos seres vivos e problemas associados com presença de resíduos de agrotóxicos em alimentos. O seu uso cada vez crescente tem causado severos riscos à saúde pública, principalmente em trabalhadores rurais que manuseiam esses produtos químicos diariamente (Cassal et al., 2014). Por serem potencialmente tóxicos à saúde humana, os agrotóxicos podem induzir a efeitos deletérios, tais como: câncer, efeitos sobre a reprodução, imunidade ou sistema nervoso. Estes efeitos vão depender da quantidade de produto químico a qual a pessoa foi exposta e também da via de exposição (WHO, 2015). Nesse sentido, Saadi e Abdollahi (2012) enfatizam que estudos sobre a relação exposição a agrotóxicos e infertilidade humana devem ser realizados, principalmente, para elucidar os efeitos adversos aos agricultores expostos a essas substâncias em regiões menos desenvolvidas.

Devido aos riscos associados a grandes concentrações de agrotóxicos em alimentos, no Brasil existe um órgão responsável por monitorar estes resíduos em alimentos: Programa de Análise de Resíduos de Agrotóxicos em Alimentos (PARA). O PARA foi criado pela Agência Nacional de Vigilância Sanitária (ANVISA) no intuito de fiscalizar a presença desses resíduos em alimentos, visto que o país apresenta um grande potencial agrícola e é considerado o maior consumidor de agrotóxicos no mundo (Jardim e Andrade, 2008; Cassal et al., 2014). Apesar de serem perigosos para a saúde humana, os agrotóxicos são essenciais para manter os cultivos livres de pragas e, consequentemente, garantir os alimentos para as refeições diárias da sociedade.

\section{Conteúdos químicos aplicados ao tema agrotóxicos}

\section{Química Ambiental e agrotóxicos}

Os agrotóxicos quando em contato com o meio ambiente podem sofrer processos de transferência (processo em que realoca a molécula sem alterar sua estrutura) ou de degradação (processo em que altera a estrutura química da molécula de agrotóxicos). Os processos de transferência podem ser do tipo erosivo, de lixiviação, absorção, adsorção, volatilização e deriva física, ocasionando diversas consequências como, por exemplo, o movimento da ação dos ventos. Já em processos de degradação eles podem ser classificados em 

fotoquímica, microbiana, químicos e
metabolismo. Dentre as consequências pertinentes a esse processo pode-se citar a degradação microbiana. Segundo Delcour et al. (2015), o processo de volatilização é um dos principais responsáveis pela presença de agrotóxicos na atmosfera, devido à transformação da substancia liquida ou sólida em uma fase gasosa. Já o processo de transporte de agrotóxicos é influenciado por fatores como sazonalidade de precipitação, intensidade e aumento de temperatura, e mudanças no uso do solo. Embora alguns agrotóxicos tenham um tempo de vida muito longo no ambiente, a maioria sofre reações químicas e bioquímicas em questão de dias ou meses, produzindo novas substâncias. Em função disso, baseado no tempo de meia-vida, os agrotóxicos são classificados em não persistente, moderadamente persistente e persistente (Baird e Cann, 2011).

Alguns fatores, como propriedades físicoquímicas dos agrotóxicos, bem como quantidade e frequência do uso, metodologias de aplicação, características bióticas e abióticas do meio e também condições climáticas, são pontos que podem influenciar no tempo de permanência dessas substâncias biocidas no meio ambiente. De acordo com Ribas e Matsumura (2009), estas são condições que variam de acordo com o produto e também com a forma de aplicação. Por esse motivo, não se pode determinar um modelo para explicar o comportamento desses biocidas e nem sua interação com o ambiente.

Os benefícios oriundos do uso de agrotóxicos, tanto na agricultora quanto em domicílios, são os mais variados possíveis. Entretanto, a utilização constante e excessiva de tais substâncias pode acarretar em uma resistência dos próprios organismos vivos ao princípio ativo do produto aplicado, como também pode ocasionar diversos problemas ambientais e à saúde dos seres vivos em geral. Segundo Botega (2011), a contaminação ambiental e humana pelo uso indiscriminado de agrotóxicos está longe de ser um problema simples, pois são situações que recaem sobre aspectos de ordem social, econômica e cultural.

Em estudos realizados por Feldman e Kepner (2010), observou-se uma estreita ligação dos agrotóxicos e os distúrbios de desenvolvimento e aprendizagem de crianças.
Exposição das mães dessas crianças a essas substâncias causaram atrasos no desenvolvimento cognitivo, déficit de atenção, hiperatividade e autismo.

No cenário atual, uma saída para esses problemas é o uso otimizado de agrotóxicos para reduzir a contaminação ambiental, aumentar sua eficácia contra a praga-alvo e, principalmente, reduzir a resistência a essas substâncias, bem como o ressurgimento de pragas (Gill e Garg, 2014).

Portanto, o uso da Ciência Química tem sido reconhecido como um dos contribuintes capazes de favorecer 0 desenvolvimento sustentável mediante uma "Química sensível" (lyere, 2008). A prática da Educação Ambiental nas escolas, segundo Obasoro et al. (2013), é importante para o desenvolvimento de uma sociedade sustentável e saudável, principalmente porque ela faz menção a várias facetas da vida humana, ecologia, transportes, recursos, alimentos, produção, entre outros.

\section{Química Analítica e agrotóxicos}

No ano de 2001, sob a coordenação da ANVISA, vários órgãos governamentais se uniram para criar um programa nacional de monitoramento de resíduos de agrotóxicos em alimentos, principalmente em matrizes como verduras e frutas consumidas no país. O projeto denominado Programa de Análise de Resíduos de Agrotóxicos (PARA) tem por finalidade "avaliar continuamente os níveis de agrotóxicos presentes em matrizes alimentares, colocando o governo a par da questão da segurança alimentar, evitando, assim, possíveis danos à saúde da população brasileira" (Peres et al., 2003).

Para isso, o PARA também buscou elaborar Procedimentos Experimentais Padronizados (POP's), que relacionam aspectos gerenciais do programa e também sobre procedimentos a serem seguidos a respeito de coleta e remessa das amostras pelos laboratórios onde serão analisadas. É realizada primeiramente a amostragem (coleta das amostras de alimentos segundo os parâmetros de amostragem do POP's). A segunda etapa consiste no preparo dessas amostras coletadas (a matriz passa por diversos tratamentos analíticos, tais como: extração de analito, 
remoção dos interferentes e concentração). E a última etapa consiste na devida homogeneização das amostras sendo realizadas, posteriormente, análises de multirresíduo ou de determinação de ditiocarbamatos (Peres et al., 2003).

Como estratégia de ensino de alguns conceitos de Química Analítica associados aos agrotóxicos, Schlegel e Hemminger (2006) propuseram atividades que ressaltam os seguintes objetivos: cálculo da dose de um agrotóxico mediante os níveis de ingestão de alimentos; determinação de concentrações de resíduos de agrotóxicos; avaliação da segurança dos níveis de resíduos de agrotóxicos em alimentos e; avaliação dos custos e benefícios de alimentos orgânicos em comparação aos convencionais. Além de a proposta ressaltar aspectos da química analítica, também alerta os alunos quanto à segurança alimentar, pois, segundo Barret (2006), as crianças estão mais vulneráveis à exposição dessas substâncias do que os próprios adultos, devido a estas consumirem mais alimentos durante a fase de desenvolvimento. Esse exemplo demonstra claramente o objetivo da Química Analítica de abranger qualquer tipo de teste para fornecer informações pertinentes a uma matriz, no que tange a sua composição química (Higson, 2009), além de alertar as crianças sobre a problemática alimentos e agrotóxicos.

O método analítico "QuEChERS" tem sido amplamente utilizado pela comunidade científica internacional que analisa resíduos de agrotóxicos em alimentos, uma vez que diversos trabalhos na área tem utilizado o método em sua forma original ou com algumas adaptações. É uma técnica bastante eficaz, barata e simples quando se trata de análise de resíduos de agrotóxicos em matrizes complexas como os alimentos (Chiaradia, 2009). Em matrizes complexas como o solo, um método alternativo para extração de substâncias como os agrotóxicos, é a extração Sólido-Líquido com partição a baixa temperatura (método análogo ao de extração líquido-líquido com partição em baixa temperatura). A vantagem desta técnica é que reduz etapas adicionais de limpeza do analito antes da leitura em Cromatógrafo Gasoso (Soares et al., 2015). Além das técnicas de determinação de agrotóxicos em diversas matrizes, existe uma preocupação com a forma retirá-los do ambiente. Uma maneira de remediar ambientes contaminados por agrotóxicos tem sido a prática de biodegradação pelo uso de microrganismos. Atualmente, tem recebido cada vez mais atenção devido à sua eficiência, baixo custo e por ser ambientalmente correto (Hossain et al., 2015).

A utilização do tema para estudar conceitos de Química Analítica é uma maneira de mostrar aos graduandos como acontecem os procedimentos experimentais para identificação de resíduos de agrotóxicos em diversas matrizes. Ademais, segundo Higson (2009), a presente área fornece dados qualitativos e/ou quantitativos de qualquer amostra investigada que facilita a compreensão do analito detectado (por exemplo, algum tipo de agrotóxico). São conceitos como: amostragem, preparo de amostras, extração de analito, métodos analíticos, conservação de amostras, programa de análise de agrotóxicos no Brasil e outros assuntos.

\section{Química Orgânica e agrotóxicos}

Os primeiros inseticidas naturais orgânicos utilizados pelo ser humano foram a nicotina e a rotenona. A nicotina é extraída das folhas de fumo e foi utilizada a partir do século XVII para combater insetos em jardim. A rotenona, em contrapartida, é isolada somente a partir das raízes de Derris elliptica e sua aplicabilidade era no combate às lagartas desde o final do século XIX (Braibante e Zappe, 2012). A nicotina e a rotenona (Figura 1) são compostos orgânicos que apresentam em sua fórmula estrutural elementos como carbono, hidrogênio, oxigênio e nitrogênio. A nicotina apresenta uma estrutura de cadeia cíclica enquanto que a rotenona é uma cadeia caracterizada como mista. Ademais, as estruturas mencionadas apresentam, respectivamente, os grupos funcionais amina e éter. Segundo Solomons e Fryhle (2012), os grupos funcionais são responsáveis por determinar a reatividade e propriedades previsíveis às moléculas.

\section{$<$ Figura 1>}

Outros exemplos de compostos orgânicos dentre os agrotóxicos mais utilizados são os inseticidas: organofosforados, organoclorados e carbamatos. Os organofosforados são compostos orgânicos derivados do Ácido Fosfórico e apresentam como principal característica uma alta atividade biológica. $\mathrm{O}$ 
Malation é um exemplo de organofosforado comercializado e que apresenta fórmula molecular $-\mathrm{C}_{10} \mathrm{H}_{19} \mathrm{O}_{6} \mathrm{PS}_{2}$ - e nomenclatura oficial Fosforoditioato de 0,0-dimetil S-1,2 bis (etoxicarbonil) - etila (Silva et al., 2013). Os organofosforados ganharam popularidade em todo o mundo em função dos organoclorados serem mais persistentes e altamente prejudiciais ao meio ambiente (McCauley et al., 2006). Os organoclorados, em contrapartida, são compostos orgânicos mais persistentes ao meio ambiente e que apresentam em sua fórmula radicais Cloro. O DDT é um exemplo de organoclorado proibido inclusive no Brasil. Sua fórmula molecular é $-\mathrm{C}_{14} \mathrm{H}_{9} \mathrm{Cl}_{5}-\mathrm{e}$ sua nomenclatura oficial é Dicloro difeniltricloroetano (Silva et al., 2013). Devido a sua toxicidade e alta persistência nos ambientes aquático e terrestre, os organoclorados ganharam uma significativa atenção em termos globais (Ali et al., 2014). Por fim, os carbamatos são compostos orgânicos derivados do Ácido Carbâmico e apresentam baixa toxicidade em longo prazo. O Carbaril, por exemplo, é um carbamato que possui fórmula molecular $\mathrm{C}_{12} \mathrm{H}_{11} \mathrm{NO}_{2}-\mathrm{e}$ nomenclatura oficial 1-naftil metilcarbamato (Silva et al., 2013). Entretanto, o seu uso intensivo na agricultura moderna tem causado preocupação pública em relação ao meio ambiente e a segurança alimentar (Morais et al., 2011).

Além dos exemplos de compostos orgânicos presentes na composição dos agrotóxicos, é importante salientar as reações químicas que levam à sua degradação, como por exemplo, o DDT em DDD. Essas reações são de oxidação, redução, hidrólise e fotólise, e que são determinadas pelas propriedades físico-químicas dos agrotóxicos e o comportamento ambiental (água, ar, solo e biota) em que ele está inserido (Zacharia, 2011).

Partindo-se desses exemplos de agrotóxicos, tanto os naturais quanto os sintéticos, o professor de Química Orgânica pode explorar conceitos como: funções orgânicas, nomenclatura oficial e comum, fórmulas estrutural e molecular, ligações químicas e entre outros assuntos. Além de tais conceitos, segundo Solomons e Fryhle (2012), a Química Orgânica tem sua importância na composição de tecidos de plantas, nos neurônios de animais e também na composição dos alimentos que consumimos todos os dias.

\section{Materiais didáticos e o Ensino de Química}

Em virtude dos vários desafios enfrentados pelos professores no tratamento de conteúdos químicos em sala de aula, muitos pesquisadores estão desenvolvendo materiais didáticos no intuito de facilitar o trabalho do educador durante o processo ensinoaprendizagem. Nesse sentido, Santos (2007) diz que a utilização de unidades temáticas (UTs) na produção de materiais didáticos de Química tem gerado resultados interessantes porque promove uma melhor aprendizagem e também auxilia o trabalho do professor.

Em se tratando da temática "agrotóxicos e meio ambiente", Adaime et al. (2014) propuseram e verificaram que a utilização de materiais didáticos como jogo, blog, folder e cartilha para capacitar e difundir o conhecimento sobre agrotóxicos é uma maneira de fazer com que os alunos reflitam sobre o assunto e se tornem jovens multiplicadores na comunidade em que vivem. Ainda segundo os autores, a produção da cartilha, em especial, com base nas histórias vividas pelos alunos, refletiu o quanto houve uma melhora no conhecimento dos envolvidos quanto aos agrotóxicos (informações científicas pertinentes ao tema). Isso denota que o uso de materiais didáticos aliados a unidades temáticas como os agrotóxicos na educação Química pode contribuir na evolução conceitual dos alunos em sala de aula, bem como na propagação do conhecimento para comunidade externa (ressaltando o papel social dos educandos).

Em contrapartida, Silva et al. (2014) abordaram em seu trabalho investigativo o desenvolvimento, avaliação e aplicação de um jogo didático de foco investigativo no intuito de abordar conceitos de química inorgânica no Ensino Médio (tabela periódica e funções inorgânicas). Segundo os autores, a estratégia de se utilizar jogos didáticos no ensino de Química favorece tanto o processo ensinoaprendizagem quanto proporciona o diálogo em sala de aula. Ainda sobre o uso de jogo educativo no ensino de Química, Silva et al. (2011) propuseram o jogo "Sudokímica" como ferramenta suplementar no processo ensinoaprendizagem de alunos do Ensino Médio através da resolução de problemas químicos. No entanto, os autores ressaltaram que uso de jogos 
didáticos não devem ser encarados como substitutos de outros métodos de ensino, mas sim como recurso complementar e motivador durante o ensino dos educandos.

Para Lima e Mesquita (2008), o uso de programas de TV no contexto da sala de aula, como mecanismo facilitador do processo ensino e aprendizagem, favorece tanto o debate de assuntos químicos quanto permite a formação dos educandos para a cidadania (objetivo preconizado atualmente pela educação nacional). Segundo os resultados alcançados pelos autores, aliar os recursos audiovisuais com programas televisivos, durante o ensino de Química, favoreceu uma relação diferenciada entre os alunos, professor e conteúdo químico abordado.

Assim, conforme apontam Buffolo e Rodrigues (2015), conceitos químicos quando trabalhados de forma articulada com o contexto social do educando, estes acabam apresentando maior interesse pelos conteúdos e, naturalmente, conseguem assimilá-los melhor. Em contrapartida, Tenaw (2015) propõe estratégias ativas de ensino de química para a eficácia do processo de aprendizagem, tais como: uso de modelos durante o ensino; utilização das TIC (Tecnologia de Informação e Comunicação); uso da apreciação e avaliação; pontos para discussão; possuir preparações profissionais e professores altamente qualificados e outros.

\section{PARTE EXPERIMENTAL}

Ao longo da realização do presente trabalho pretendeu-se, inicialmente, investigar referenciais teóricos que faziam menção ao Ensino de Química associado a uma temática social e ambiental: os agrotóxicos. Tal investigação teve como principal propósito nortear os caminhos para a produção de uma intervenção didática como ferramenta de apoio para os educadores de disciplinas específicas do curso de Licenciatura em Química. Para contribuir na contextualização do tema e, consequentemente, na produção de um material didático, também foi executada uma entrevista semi-estruturada com seis professores da área da Química que lecionam as disciplinas de Química Ambiental, Analítica e Orgânica.

As entrevistas ocorreram no primeiro semestre de 2013, especificamente nos meses de março e abril. As questões abordadas no questionário buscaram identificar quais as concepções dos educadores a respeito da terminologia agrotóxicos, inclusive, da forma com a qual eles obtiveram essa concepção. Além disso, também buscaram verificar se esses professores já trabalharam suas disciplinas específicas a partir da temática em foco e como os conteúdos químicos das disciplinas de Química Ambiental, Analítica e Orgânica poderiam ser trabalhados por meio dessa temática sugestiva.

Com base nessas informações, a estruturação do caderno didático seguiu as sugestões apontadas pelos professores juntamente com informações de referenciais teóricos sobre o assunto.

\section{RESULTADOS E DISCUSSÃO}

\section{Dados obtidos nas entrevistas com os docentes}

Os seis docentes entrevistados foram questionados quanto à concepção que possuem sobre o tema agrotóxicos. Dessa totalidade, quatro admitiram que a concepção do termo estivesse relacionada a um produto utilizado na agricultura para fins de aumento de produtividade, além de combater pragas em lavouras. Em contrapartida, dois docentes acreditam que os agrotóxicos são substâncias químicas utilizadas não somente na agricultura, mas também na pecuária e para fins domissanitários, no intuito de reduzir pragas. Tendo em vista essas duas vertentes, observase que o conceito não é amplo pela maioria dos entrevistados. Um material didático para dar suporte aos professores será de fundamental importância para que a contextualização do tema seja uma ferramenta para o ensino de seus conteúdos e a aproximação da realidade do aluno na aprendizagem significativa da Química.

Daí a necessidade de se discutir temas relevantes como os agrotóxicos no contexto escolar, pois a maioria das abordagens em artigos científicos se relaciona a aspectos químicos e ambientais associados aos agricultores e aplicadores de tais produtos e aos riscos que essas pessoas estão expostas. Dificilmente são encontrados trabalhos que relacionam a temática a uma abordagem pedagógica para as aulas de Química. O ensino 
de Ciências articulado a uma abordagem contextualizada, segundo Genovese e Pessoa (2013), é uma maneira de provocar mudanças na mentalidade educacional dos indivíduos envolvidos nesse contexto. No contexto das faculdades da Califórnia, Spring (2009) diz que nas competências básicas como requisito para um bom sucesso do aluno está o Ensino e Aprendizagem Contextualizada (EAC), pois é uma estratégia promissora que envolve ativamente os alunos, como também promove a melhoria de aprendizagem e desenvolvimento de competências.

$\mathrm{Na}$ segunda questão da entrevista investigou-se como os educadores obtiveram suas concepções acerca dos agrotóxicos. Foi possível observar que os professores entrevistados obtiveram a concepção de agrotóxicos das mais diversas formas possíveis, desde a leitura de artigos de periódicos sobre o assunto até pelos próprios familiares que trabalhavam e/ou moravam no campo. Pelos resultados obtidos, a maioria adquiriu a concepção do termo por meio de leitura de artigos científicos que tratam o assunto. Daí a importância de se trabalhar a temática no contexto da sala de aula, a fim de promover a melhor divulgação e visualização do assunto tanto pelos professores quanto pelos alunos. Carraro (1997), por exemplo, trabalhou o tema agrotóxicos com enfoque na Educação Ambiental sugerindo diversas atividades educativas (leitura de reportagens sobre agrotóxicos; pesquisa de campo; análise de rótulos e/ou embalagens vazias de agrotóxicos pelos alunos; atividade experimental e exercícios de fixação), tanto para o ensino fundamental quanto para o médio.

Ao verificar junto aos professores como eles trabalham suas disciplinas específicas com seus alunos, a maioria apontou que suas aulas tem característica expositiva dialogada e, sempre que possível, partem de uma abordagem contextualizada. É possível perceber que a maioria dos professores se preocupa em aproximar os conceitos científicos ao cotidiano do aluno como objetiva a terminologia contextualização, entretanto não souberam explicar de que forma trabalham a proposta. Cavalcanti et al. (2010) perceberam que a utilização do tema contextualizador aliado a algumas estratégias didáticas (leitura, experimentação, estudo de meio, grupos de discussão e dentre outros) promoveu uma participação mais ativa dos estudantes e, principalmente, favoreceu a socialização de ideias, participações e mudanças positivas nas ideias iniciais que os alunos tinham sobre os agrotóxicos.

Ainda sobre a questão das metodologias aplicadas pelos docentes nas aulas de Química, foi perguntado durante a entrevista se os mesmos utilizam ou já utilizaram em algum momento a temática no tratamento de conteúdos específicos da Química. Pôde-se constatar que a contextualização dos agrotóxicos às disciplinas específicas em foco é bem evidente, principalmente em Química Ambiental e Analítica. Isso ocorre possivelmente porque os professores dessas duas áreas já trabalharam com projetos de pesquisa voltados para o tema agrotóxicos.

Por fim, foram perguntados quais conteúdos da Química poderiam ser trabalhados a partir do estudo dos agrotóxicos. A Tabela 1 apresenta os conteúdos químicos apontados pelos docentes das áreas de Química Ambiental, Analítica e Orgânica que poderiam ser trabalhados em sala de aula a partir da contextualização do tema agrotóxicos. A última questão das entrevistas foi de fundamental importância para a produção do caderno didático, pois orientou os caminhos para se abordar conteúdos da Química associados aos agrotóxicos e também comprovou a riqueza do tema quando se trata da Ciência Química.

\section{$<$ Tabela 1>}

\section{Caderno didático - "Agrotóxicos: uma abordagem contextualizada em Química Ambiental, Analítica e Orgânica"}

O caderno didático "Agrotóxicos: Uma abordagem contextualizada em Química Ambiental, Analítica e Orgânica", produzido ao longo dessa investigação, é uma ferramenta de apoio como resultado da pesquisa. O material apresenta trinta e uma páginas, sendo cada uma das áreas específicas da Química abordadas em capítulos separados. Essa produção didática foi construída com base em dados obtidos em entrevistas com docentes e também de referenciais teóricos da área de agrotóxicos. Sua capa está apresentada na Figura 2. 


\section{$<$ Figura 2>}

Os assuntos abordados no material são: manejo de agrotóxicos no estado de Goiás e no Brasil; riscos de intoxicação causados pelo uso inadequado e exposição a essas substâncias; principais cultivos no estado de Goiás; técnicas de extração para amostras que contém agrotóxicos; nomenclatura de compostos orgânicos partindo-se de exemplos de agrotóxicos e; entre outros assuntos. A disposição dos conteúdos no caderno está estrategicamente organizada de forma a mostrar tanto para o aluno quanto para o professor que é possível trabalhar a contextualização e a interdisciplinaridade por meio do tema social "agrotóxicos", conforme sumário na Figura 3.

\section{$<$ Figura 3>}

Além disso, o material conta com ilustrações coloridas a respeito do assunto no intuito de conquistar a leitura do aluno e também com atividades sugestivas ao final do caderno para que o professor possa utilizá-las durante a realização de suas aulas específicas. Aliar os conceitos científicos às ilustrações foi uma estratégia para facilitar o aprendizado do aluno, bem como tornar agradável a leitura sobre o assunto: Agrotóxicos e Química.

O caderno traz atividades sugestivas (Figura 4) elaboradas a partir do estudo dos agrotóxicos que podem ser trabalhados com os alunos em cada disciplina específica do curso de Licenciatura em Química (Química Ambiental, Analítica e Orgânica).

\section{<Figura 4>}

Também são apresentadas atividades sugestivas (Figura 5 ) que podem ser trabalhadas a interdisciplinaridade partindo-se do estudo dos agrotóxicos. Essa seção do caderno didático merece especial destaque porque mostra aos educadores que é possível tanto trabalhar a contextualização quanto a interdisciplinaridade no ensino de Química explorando-se um assunto que é tão importante no Brasil: uso dos agrotóxicos e seus riscos à saúde pública. Assim, a difusão do tema através do caderno didático é uma forma de alertar os alunos quanto aos riscos que essas substâncias oferecem à saúde humana, bem como torna os alunos e professores como multiplicadores dos saberes científicos abordados no caderno, conforme relatos de Buffolo e Rodrigues (2015).

\section{$<$ Figura 5>}

De uma forma geral, o caderno didático abrange assuntos da Química com uma linguagem simples, porém valorizando o caráter científico da temática utilizada. Além disso, o material ressalta aspectos da agricultura goiana, bem como os cuidados que devem ser tomados pelas pessoas que mantém contato diário com essas substâncias nocivas. A maioria das produções de materiais educativos na área da Química está voltada para o público do ensino médio (cartilhas educativas e jogos lúdicos sobre agrotóxicos). Botega (2011), por exemplo, trabalhou o tema agrotóxicos aliado à educação ambiental com o intuito de produzir um material didático com alunos do ensino fundamental. A cartilha educativa produzida, segundo apontamentos do autor, contém histórias relatadas pelos próprios alunos no que diz respeito aos agrotóxicos e o meio ambiente. Além disso, a produção do material pelos próprios alunos foi uma estratégia que possibilitou uma aproximação dos mesmos com a realidade que os cercam.

Ainda sobre a educação ambiental, em contrapartida, Rezzadori e Cunha (2006) propuseram um trabalho de pesquisa em que o próprio educador produz seu material didático para utilizar em suas aulas de Química. O material produzido se assemelha a um livro didático, porém com uma abordagem coerente com as necessidades dos alunos partindo-se de temáticas ambientais (lixo, chuva ácida, poluição e outros). Além de facilitar o trabalho do educador, a proposta também cumpre com as exigências preconizadas pelas diretrizes curriculares.

Já Silva et al. (2014) apontam como proposta didática a elaboração e aplicação de um jogo lúdico sobre conceitos de Química Inorgânica para o ensino médio. O material produzido foi aplicado com alunos de uma escola pública e, segundo os autores, se mostrou eficaz, pois melhorou a interação em sala de aula, ampliou os conhecimentos dos alunos e promoveu um diálogo da pesquisadora 
com os alunos durante a realização da atividade.

$\mathrm{Na}$ percepção de Fernandes e Stuani (2015), a temática agrotóxicos pode ser discutida em diferentes níveis de ensino e de conhecimento. Por exemplo, no Ensino de Ciências, podem ser trabalhados conteúdos conceituais e de cunho social, ambiental, político, ético, econômico e histórico, bem como pode ser dado ênfase a conceitos importantes para a formação de professores mais críticos e ativos na sociedade.

É notório que produções de materiais didáticos (cartilhas, apostilas, blogs e jogos lúdicos) para o público do Ensino Médio no que concerne o ensino de Química é bastante expressivo, tanto pelo uso do tema agrotóxicos quanto por outros temas ambientais. Assim, a criação de um caderno didático, conforme apresentado nos resultados dessa pesquisa, voltado para o Ensino Superior se tornou importante para engajar futuras produções educativas sobre agrotóxicos, inclusive, para esse público. Além do mais, a iniciativa favorece uma maior disseminação das informações sobre os agrotóxicos pelos acadêmicos, professores e comunidade em geral.

\section{CONCLUSÕES}

O ensino de Química, seja ele no nível médio ou no nível superior, é um grande desafio tanto para o professor quanto para o aluno, pois a maior dificuldade dos educandos está no caráter abstrato que a área do conhecimento é caracterizada. Já para os professores, o desafio está em como trabalhar conteúdos de Química de forma agradável, mas sem comprometer as concepções científicas que norteiam a disciplina. Além disso, as metodologias de ensino tradicionalistas (exposição teórica e maçante de conteúdos da Química), em muitas situações, não conseguem motivar o aluno e nem mostrar o quão interessante a Química pode se tornar.

O presente trabalho produzido (caderno didático) possibilitou vislumbrar 0 assunto "agrotóxicos aliado à Química" de forma agradável sem comprometer os conceitos científicos da área da Química. Ademais, a investigação se tornou pertinente ao passo que favoreceu um levantamento panorâmico da importância dada pelos docentes na utilização de eixos temáticos sociais e ambientais na área da Química. Ainda mostrou que diversos trabalhos científicos foram e estão sendo elaborados no sentido de tratar a periculosidade associada ao uso indiscriminado de agrotóxicos pelas pessoas, tanto na agricultura quanto em domicílios. Nesse sentido, a partir dos resultados apontados neste trabalho, o professor consegue fazer uma ponte entre o conteúdo programático previsto e o contexto social do aluno envolvido.

Com o trabalho foi possível observar que os agrotóxicos podem ser bem explorados extraindo-se diversos conteúdos químicos. O tema ainda é pouco explorado em sala de aula pelos professores, entretanto esse trabalho trouxe um novo olhar ao tema e destacou sua importância regional e, principalmente, o seu grande potencial para contextualização nas diversas áreas da Química. Os dados obtidos contribuíram muito para a construção do caderno didático, inclusive, no que diz respeito às sugestões de atividades pelos docentes.

\section{AGRADECIMENTOS}

Ao Instituto Federal de Goiás - Câmpus Itumbiara, aos docentes que participaram dessa pesquisa, ao Programa de Educação Tutorial ("PET Química: Educação, Ambiente e Sociedade") e ao MEC/FNDE pela bolsa concedida.

\section{REFERÊNCIAS}

1. Adaime, M. B.; Botega, M. P.; Prestes, O. D.; Zanella, R. Ciência e Natura, 2014, v. 36, n. 2, p. 250-257.

2. Aktar, M. W.; Sengupta, D.; Chowdhury, A. Interdisciplinary Toxicology, 2009, v. 02, $n^{\circ} 01$, p. 1-12.

3. Al-Sabbagh, S. Senior Educational Research, 2009, p. 1-14.

4. Ali, U.; Syed, J. H.; Malik, R. N.; Katsoyiannis, A.; Li, J.; Zhang, G.; Jones, K. C. Science of The Total Environment, 2014, v. 476477, p. 705-717.

5. Baird, C.; Cann, M. Pesticidas. $4^{a}$ ed. Porto Alegre: Bookman, 2011, cap. 10.

6. Barret, J. R. Environ Health Perspect, 2006, v. 114, $n^{\circ}$ 2, p. 1-3.

7. Botega, M. P. Dissertação de mestrado. 
Santa Maria - Rio Grande do Sul, Brasil, 2011.

8. Braibante, M. E. F.; Zappe, J. A. Química Nova na Escola, 2012, v. 34, n.1, p. 10-15.

9. Buffolo, A. C. C.; Rodrigues, M. A. Investigações em Ensino de Ciências, 2015, v. 20, $\mathrm{n}^{\circ} 01$, p. 1-14.

10. Carraro, G. Área de Educação Química. Universidade Federal do Rio Grande do Sul, Porto Alegre, 1997, p. 95.

11. Cassal, V. B.; Azevedo, L. F. de; Ferreira, R. P.; Silva, D. G. da; Simão, R. S. Revista REGET, 2014, v. 18, n. 1, p. 437-445.

12. Cavalcanti, J. A.; Freitas, J. C. R. de; Melo, A. C. N. de; Freitas-Filho, J. R. de. Química Nova na Escola, 2010, v. 32, n.1, p. 31-36.

13. hassot, A. I. Universidade do Vale do Rio dos Sinos, Rio Grande do Sul. Revista Brasileira de Educação, 2003, n² 22, p. 89-100.

14. Chassot, A. Pra que $(\mathrm{m})$ é útil o ensino? $2^{\mathrm{a}}$ ed. Canoas: Editora ULBRA, 2004. 172 p.

15. Chiaradia, M. C. Tese de doutorado. Universidade de Campinas (Unicamp), Campinas, SP, Brasil, 2009.

16. Cooper, J.; Dobson, H. Crop Protection, 2007 , v. 26 , p. $1337-1348$.

17. Delcour, I.; Spanoghe, P.; Uyttendaele, M. Food Research International, 2015 , v. 68, p. 715.

18. Fernandes, C. dos S.; Stuani, G. M. Educação \& Realidade, Porto Alegre, 2015, v. 40, n. 3, p. 745-762.

19. Genovese, C. L. de C.; Pessoa, J. de M. Revista Educação, Cultura e Sociedade. 2013, v. 3, n. 2, p. 323-336.

20. Gill, H. K.; Garg, H. Intech, 2014, p. 187230.

21. Higson, S. Química Analítica. São Paulo: McGraw-Hill, 2009. p. 454.

22. Hossain, M. S.; Chowdhury, M. A. Z. Pramanik, M. K.; Rahman, M. A.; Fakhruddin, A. N. M.; Alam, M. K. Appl Water Sci, 2015, v. 05, p. 171-179.

23. Iyere, P. A. Chemical Education Today, 2008 , v. $85, n^{\circ} 12$, p. $1604-1606$.

24. Jardim, I. C. S. F.; Andrade, J. de A. Química Nova, 2008, v. 32, n04, p. 996-1012.

25. Lima, T. da C.; Mesquita, N. A. da S. Periódico Tchê Química, 2008, v. 05, $\mathrm{n}^{\circ} 10$, p. 14-20.

26. Marques, C. A.; Silva, R. M. G. da. Química Nova, 2013, v. 36, n4, p. 600-606.

27. McCauley, L. A.; Anger, W. K.; Keifer, M.; Langley, R.; Robson, M. G.; Rohlman, D. Environ Health Perspect, 2006, v. 114, n. 6, p. 953-960.
28. Morais, S.; Dias, E.; Pereira, M. de L. The Impacto of Pesticides, 2011, p. 21-38.

29. Obasoro, C. B.; Oyinloye, O. A.; Ilesanmi, A. A. African Research Review, 2013, v. 7, n. 28, p. 298-306.

30. Owens, K.; Feldman, J.; Kepner, J. Pesticides and You, 2010, v. 30, $\mathrm{n}^{\circ}$ 02, p. 13-21.

31. Peres, F.; Moreira, J. C.; Dubois, G. S. Agrotóxicos, saúde e ambiente: uma introdução ao tema. Fundação Oswaldo Cruz, 2003, cap. 01.

32. Preusch, P. L. Masters Dissertation, University of Maryland, 344 p., 2009.

33. Rezzadori, C. B. D. B.; Cunha, M. B. da. Revista Varia Scientia, 2006, v. 05, n. 09, p. 177188.

34. Ribas, P. P.; Matsumura, A. T. S. Revista Liberato, 2009, v. 10, n. 14, p. 149-158.

35. Saadi, H. S.; Abdollahi, M. International Journal of Pharmacology, 2012, v. 8, p. 467-469.

36. Santos, F. M. T. dos. Experiências em Ensino de Ciências, 2007, v. 2, n. 1, p. 01-11.

37. Schwarz, C. Science Education, 2009, v. $93, n^{\circ} 4$, p. $720-744$.

38. Schlegel, B.; Hemminger, L. National Institute of Environmental Health Sciences, 2006, p. 1-10.

39. Silva, M. R. da; Campos, A. C. E. de; Bohm, F. Z. Revista Saúde e Biologia (SaBios), 2013, v.8, n.2, p. 46-58.

40. Silva, B. da; Cordeiro, M. R.; Kiill, K. B. Química Nova na Escola, 2014, v. 00, n. 00, p. 01-08.

41. Silva, C. K. O.; Nogueira, J. P. A.; Souza, H. Y. S. Periódico Tchê Química, 2011, v. 09, $\mathrm{n}^{\circ}$ 17 , p. 42-47.

42. Shamsudin, N. M.; Abdullah, N.; Yamaat, N. Procedia - Social and Behavioral Sciences, 2013, v. 90, p. 583-592.

43. Soares, C. E. S.; Neves, A. A.; Queiroz, M. E. L. R.; Oliveira, A. F.; Costa, A. I. G.; Assis, R. C.; Andrade, C. E. O. J. Braz. Chem. Soc., 2015, v. 26, nº9, p. 1990-1997.

44. Solomons, G.; Fryhle, C. B. Química Orgânica. v. 2, $10^{\mathrm{a}}$ ed. Rio de Janeiro: LTC, 2012.

45. Spring. Center for Student Success, 2009, $76 \mathrm{p}$.

46. Tenaw, Y. A. Int. J. Educ. Res. Rev., 2015, v. 03, nº3, p. 77-84.

47. UDO, M. E. Modern Applied Science, 2011 , v. $5, n^{\circ} 6$, p. $211-217$.

48. World Health Organization - WHO. Online 
Q\&A, Julho de 2015.

World - Trends in Pesticides Analysis, 2011, p.

49. World Health Organization, 1990, 01-19.

$123 \mathrm{p}$.

50. Zacharia, J. T. Pesticides in the Modern
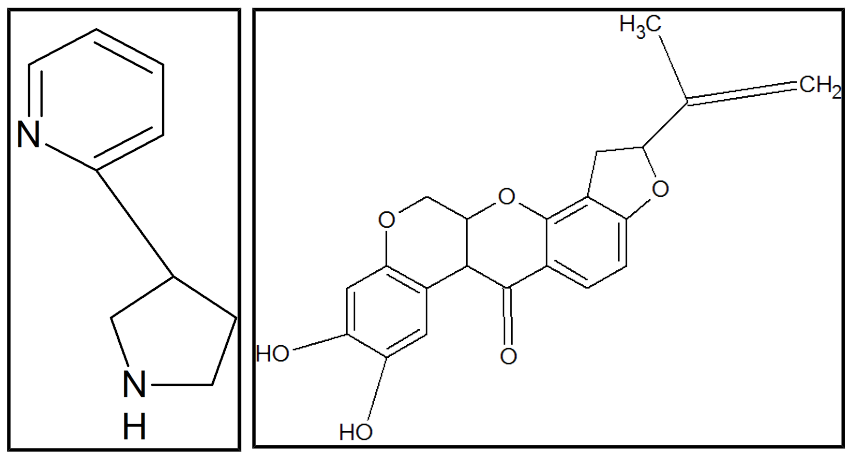

Figura 1. Estrutura da nicotina (à esquerda) e estrutura da rotenona (à direita).

Tabela 1. Conteúdos das disciplinas específicas citados nas entrevistas.

\begin{tabular}{llll}
\hline \multicolumn{1}{c|}{ Química Ambiental } & \multicolumn{1}{c}{ Química Analítica } & \multicolumn{1}{c}{ Química Orgânica } \\
\hline -Água, solos e ar; & -Análise de cátions e & - Esterioquímica \\
-Dentro do tema água & ânions; & -Configuração espacial \\
e solos podem-se & -Seminários & de moléculas; \\
abordar agrotóxicos & desenvolvidos a partir & -Sínteses orgânicas de \\
em aulas expositivas, & de temas ambientais & compostos em \\
realização de & (por exemplo, & processos industriais; \\
seminários e resolução & agrotóxicos no curso & -Identificação de \\
de exercícios. & de agronomia); & grupos funcionais em \\
-Tabela periódica a & -Soluções e & compostos orgânicos; \\
partir da temática & concentrações; & -Cultivo orgânico de \\
agrotóxicos (estrutura & -Análise quantitativa & alimentos; \\
dos organoclorados e & de substâncias & -Reações químicas; \\
seus impactos & poluentes; & - Historicidade do uso \\
negativos do seu uso & - Amostragem e & de agrotóxicos; \\
indiscriminado). & preparo de amostras; & -Cálculos \\
& -Análise instrumental & estequiométricos \\
& focada nos níveis de & -Reatividade e \\
& agrotóxicos em & solubilidade de \\
& diversas matrizes. & compostos orgânicos. \\
\hline
\end{tabular}

PERIÓDICO TCHÊ QUÍMICA • www.periodico.tchequimica.com • Vol. 13 N. 26. - ISSN 1806-0374 (impresso) • ISSN 1806-9827 (CD-ROM) • ISSN 2179-0302 (meio eletrônico) (C) 2016. Porto Alegre, RS. Brasil 


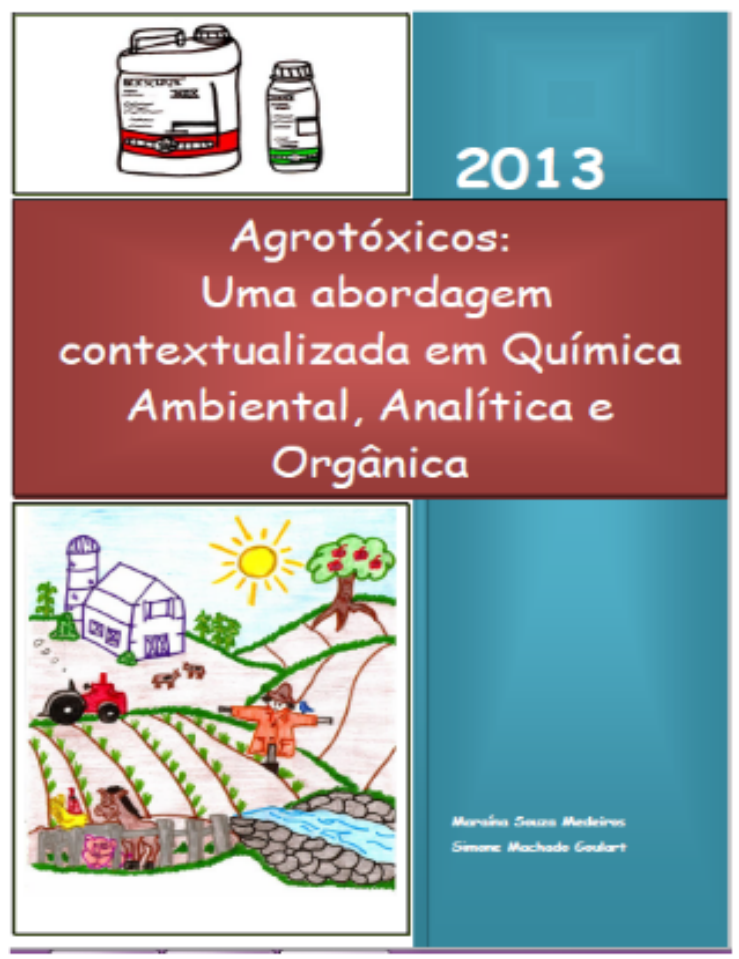

Figura 2. Capa do caderno didático produzido.

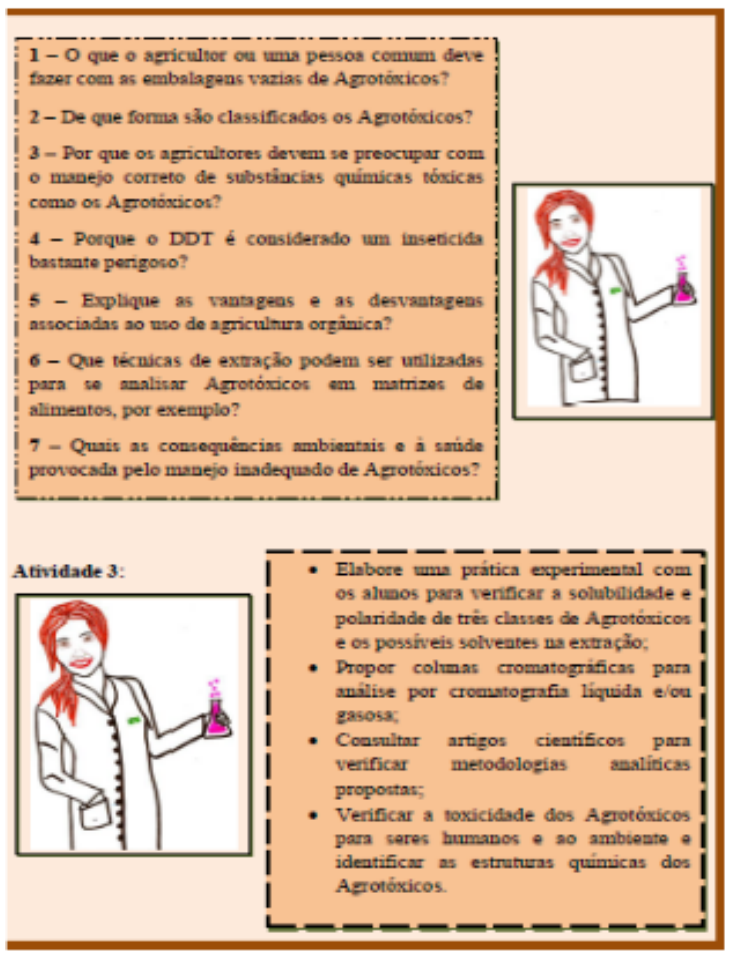

Figura 4. Seção do caderno didático com atividades sugestivas em cada área específica (Química Ambiental, Analítica e Orgânica).

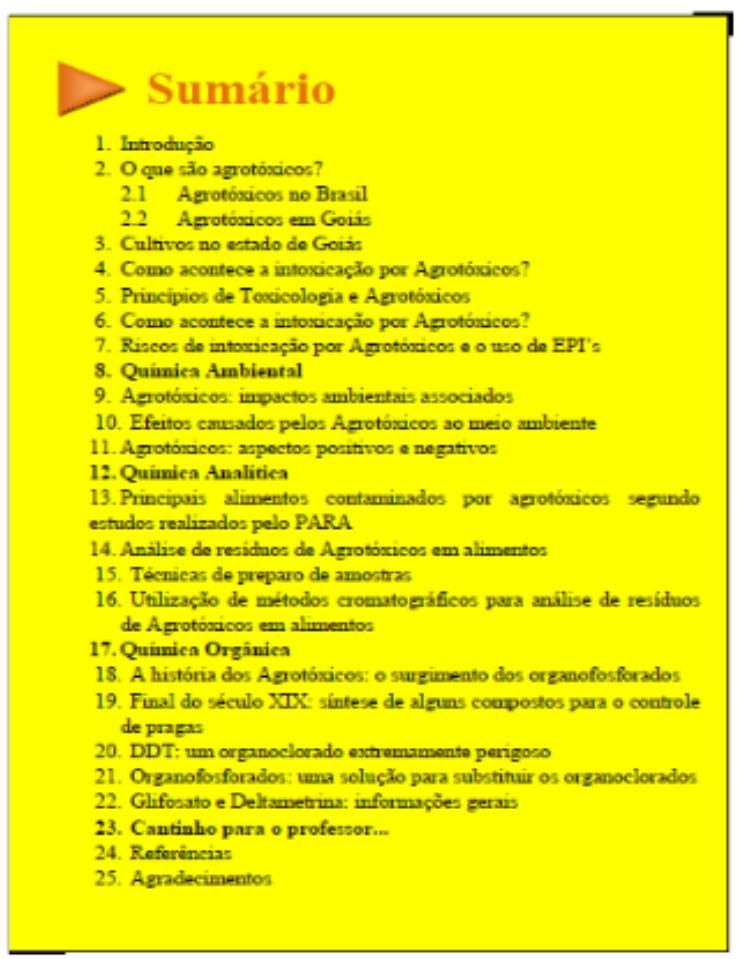

Figura 3. Assuntos abordados no caderno didático.

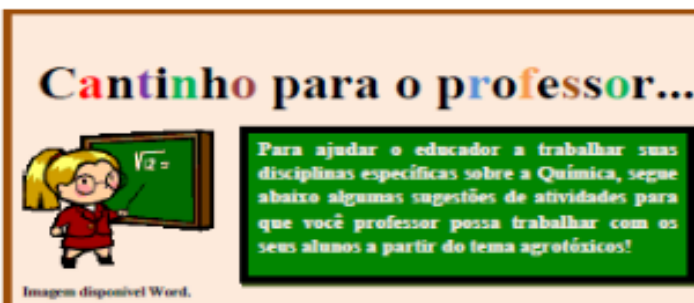

PARTE A (Arividades sugestivas que podem ser aplicadas nas três área em conjunto: Ambiental, Analitica e Orgânica)

Anividade 1:

Sugin aos seus alumos fazerem pesquisas de reportagens recentes na intemet que meacionem o uso de Agrotóxicos no Brasil. Em segude, oniente-os a deseavolverem as seguiates tarefas:

- Fasa a leinura da reportagem

- Retire os priscipais conceitos apresentados mo longo do costerido da repertagem

Encontre os principais atpectos históncos que relatam o uso de Agrotóricos desde os primórdios até a atualidade; - Por fim pesa aos alumos que elaborem um guadro conceinual urilizando figuras de revistas o os conceitos racirados da reportagem. Esve quadro conceirual permitiri aos alumos ter wan visão global da aecessidade do bomem em se criar of Agrotónticos

Atrividade 2:

Elabore e splique um questionirio para verificar os conbecimeatos adquiridos pelos alunos a partir da leinura desse caderno didático. Abasixo, segue um questionino sugestivo para ser aplicado a0s almos:

Figura 5. Seção do caderno didático com atividades sugestivas a partir do

tema "agrotóxicos" envolvendo a interdisciplinaridade.

PERIÓDICO TCHÊ QUÍMICA • www.periodico.tchequimica.com • Vol. 13 N. 26 • ISSN 1806-0374 (impresso) • ISSN 1806-9827 (CD-ROM) • ISSN 2179-0302 (meio eletrônico)

(C) 2016. Porto Alegre, RS. Brasil 